\title{
Epigenetic regulation of MAGE family in human cancer progression-DNA methylation, histone modification, and non-coding RNAs
}

\author{
Yishui Lian ${ }^{1+}$, Lingjiao Meng ${ }^{1,2+}$, Pingan Ding ${ }^{1}$ and Meixiang Sang ${ }^{1,2^{*}}$ (D
}

\begin{abstract}
The melanoma antigen gene (MAGE) proteins are a group of highly conserved family members that contain a common MAGE homology domain. Type I MAGEs are relevant cancer-testis antigens (CTAs), and originally considered as attractive targets for cancer immunotherapy due to their typically high expression in tumor tissues but restricted expression in normal adult tissues. Here, we reviewed the recent discoveries and ideas that illustrate the biological functions of MAGE family in cancer progression. Furthermore, we also highlighted the current understanding of the epigenetic mechanism of MAGE family expression in human cancers.
\end{abstract}

Keywords: MAGE, Epigenetics, Transcription regulator, E3 RING ubiquitin ligases

\section{Background}

The first member of the melanoma antigen gene (MAGE) was discovered in 1991, when Van der Bruggen et al. performed experiments to identify tumor antigens from melanoma cells [1]. The human MAGE family was divided into two categories in the light of their chromosomal location and expression pattern [2-4]. Nowadays, MAGE family was well known as tumor-associated antigens and comprises more than 60 genes, which share a conserved MAGE homology domain (MHD) [5]. Type I MAGEs are relevant cancer-testis antigens (CTAs) which contain MAGE-A, -B and -C subfamily members [6], and therefore are rarely expressed in normal adult tissues, but highly expressed in various cancers, including melanoma, breast cancer, prostate cancer, lung adenocarcinoma, esophageal squamous cell carcinoma, gastric cancer, bladder cancer, ovarian cancer, hepatocellular carcinoma, and brain cancer [7-16]. Type II MAGEs contain the MAGE-D, -E, -F, -G, $-\mathrm{H},-\mathrm{L}$, and necdin genes, which are not limited to the $\mathrm{X}$

\footnotetext{
*Correspondence: mxsang@hotmail.com

${ }^{\dagger}$ Yishui Lian and Lingjiao Meng contributed equally to this work.

${ }^{1}$ Research Center, the Fourth Affiliated Hospital of Hebei Medical University, Shijiazhuang 050017, Hebei, People's Republic of China

${ }^{2}$ Tumor Research Institute, the Fourth Affiliated Hospital of Hebei Medical

University, Shijiazhuang 050017, Hebei, People's Republic of China
}

chromosome and are expressed in various tissues, such as brain, embryonic, and adult tissues [2-4].

MAGE family has specific functions in normal development and tumor progression. Type I MAGEs express normally only in testis or placenta, and their restricted expression suggests that they may function in germ cell development. Many studies have consistently showed that MAGE-A family may play an important role in spermatogenesis and embryonic development [4]. MAGE-B4 was found to be expressed during premeiotic germ cell differentiation, indicating that MAGE proteins may also play a role in developing oocytes [17]. MAGE-A proteins were detected by immunohistochemistry in the early development of the central nervous system (CNS) and the spinal cord and brainstem of peripheral nerves, revealing that MAGE-A protein was also involved in neuronal development [18]. Type II MAGEs are highly expressed in the brain and participate in various neural processes. These MAGE proteins might perform important functions in differentiation and neurodevelopment, thus their loss of function leads to a range of cognitive, behavioral, and developmental defects [4]. However, the biological functions and underlying regulatory mechanism of MAGE family expression in cancer is still not fully understood. The 
known tumor-related functions of MAGE family were summarized in Table 1.

In this review, we summarized these exciting advances and discoveries concerning the biological functions of MAGE family in cancer progression. We also take a comprehensive look at the current understanding of the epigenetic mechanism of MAGE family expression in human cancers. This provides an outlook on cancer therapeutic approaches that target MAGE family.

\section{Biological functions of MAGEs in cancer progression} MAGEs function as regulators of E3 RING ubiquitin ligases Some studies have explored the function of MAGE proteins in cancer cells, and they were observed to promote cancer cell survival, tumor formation, and metastasis $[19,20]$. Members of all type I MAGE protein families promoted tumor cell viability and inhibited cell apoptosis, therefore providing a growth advantage to melanoma and other malignancies [21]. MAGE-A3 and A6 were critical for cancer cell survival, and MAGE-A3/ 6-TRIM28 E3 ubiquitin ligase complex was found to degrade AMPK $\alpha 1$ resulting in downregulating AMPK signaling during tumorigenesis [22].

Recently, multiple MAGE proteins were found to form complexes with RING domain proteins, such as MAGEA2/C2-TRIM28, MAGE-B18-LNX, MAGE-G1-NSE1 complexes, etc. [23, 24]. RING domain is a cysteine-rich domain that normally forms a cross-brace structure that typically coordinates two zinc ions [25]. RING domain proteins are proved to be a big E3 ubiquitin ligase family, which bind to and localize E2 ubiquitin-conjugating enzymes to substrates for ubiquitylation [26, 27]. MAGE proteins bind directly to RING domain proteins and act as scaffold of RING domain proteins to their substrates, thus regulating the ubiquitin ligase activity of RING domain proteins (Fig. 1). In particular, MAGE-A2, -A3, -A6, and -C2 were found to bind TRIM28, also known as KAP1, TIF-1beta or Krip125, therefore inducing the degradation of tumor suppressor p53 [23]. Recently, Potts and their colleagues reported MAGE-A3/6-TRIM28 complex ubiquitinates and degrades the tumor suppressor AMPK $\alpha 1$, thus leading to the inhibition of autophagy and activation of mTOR signaling [22, 28]. MAGE I binding to KAP1 induced the poly-ubiquitination and degradation of the substrate ZNF382 [29]. ZNF382 is one of KRAB domain zinc finger transcription factors (KZNFs) family member, which is involved in cell apoptosis and tumor suppression [30]. KZNFs bind the KAP1 protein and direct KAP1 to specific DNA sequences where it suppresses gene expression by inducing localized herterochromatin characterized by histone 3 lysine 9 trimethylation (H3K9me3). The binding of MAGE to KAP1 induces the degradation of ZNF382 leading to the decreased KAP1 binding to ID1 and the increased expression of oncogene ID1 [29]. Thus, it appears that cancer-specific up-regulation of MAGE family triggers ubiquitination and degradation of multiple tumor suppressors, such as p53, AMPK $\alpha 1$, and ZNF382 through binding to RING domain protein KAP1, promoting tumorigenesis and aggressive growth. Therefore, identification of novel small molecules that inhibit protein-protein interactions between MAGE and KAP1 may be a potential therapeutic strategy for cancer-bearing MAGE expression [31].

RING-box protein 1 (Rbx1), another RING domain containing protein, is a RING component of the largest E3 ligases SCF complex [32]. SCF complex consists of Rbx1, Cullin1, Skp1, and F-box protein family, and degradation of SCF-dependent proteolysis can cause a variety of diseases including cancer [32-34]. MAGE-C2 binds directly to Rbx1 and inhibits ubiquitin-dependent degradation of cyclin $\mathrm{E}$, and promotes melanoma cell cycle progression at G1-S transition [35]. In addition, MAGE-A2 was reported to associate with MDM2, a RING finger-type E3 ligase that mediates ubiquitylation of more than 20 substrates including mainly p53, MDM2 itself, and MDM4. And the interaction of MAGE-A2 with MDM2 inhibits the E3 ubiquitin ligase activity of MDM2, thus increasing the level of MDM4. However, it does not affect p53 turnover mediated by MDM2 [36]. MAGE-A11 interacts with Skp2, the substrate recognition protein of the Skp1-Cullin1-F-box E3 ubiquitin ligase, and increases Skp2-mediated degradation of cyclin A and p130, but decreases Skp2-mediated degradation of E2F1 and Skp2 self-ubiquitination by sequestering and inactivating Skp2 via forming an E2F1-MAGE-A11-Skp2 complex [37].

\section{MAGEs function as transcriptional regulators}

The binding of MAGE-C2 to KAP1 increases the interaction between KAP1 and ATM, and increased KAP1Ser824 phosphorylation. Therefore, MAGE-C2 may promote tumor growth by phosphorylation of KAP1Ser824 and the enhancement of DNA damage repair [38]. KAP1 seems to function as a molecular scaffold that coordinates at least four activities necessary for gene-specific silencing, including (a) targeting of specific promoters through the KRAB protein zinc finger motifs; (b) promotion of histone deacetylation via the NuRD/histone deacetylase complex; (c) histone H3-K9 methylation via SETDB1; and (d) recruitment of HP1 protein [39]. KAP1 also regulates DNA repair through the phosphorylation of KAP1-Serine 824 (Ser824) by ataxia-telangiectasia-mutated (ATM) kinase [40] (Fig. 2-1). As a scaffolding protein, KAP1 interacts with p53 and acts as a co-repressor of p53 expression and function. MAGE suppression decreases KAP1 complexing with p53, increases acetylation of p53, and activates $\mathrm{p} 53$ responsive reporter genes. Class I MAGE protein may promote tumor 
Table 1 The known tumor-related functions of MAGE family

\begin{tabular}{|c|c|c|c|c|}
\hline Type & Subtype & Gene name & Highly expressed tumor type & Biological functions \\
\hline \multirow[t]{19}{*}{ MAGE-I } & \multirow[t]{12}{*}{ MAGE-A } & MAGE-A1 & $\begin{array}{l}\text { Melanoma; gastric cancer; endometrial cancer; } \\
\text { esophageal squamous cell carcinoma; } \\
\text { head and neck cancer }\end{array}$ & $\begin{array}{l}\text { Activating p-C-JUN directly or through ERK-MAPK } \\
\text { pathways; Repressing transcription by binding to } \\
\text { SKIP and recruiting HDAC1 }\end{array}$ \\
\hline & & MAGE-A2 & Glioma; breast cancer & $\begin{array}{l}\text { Degradation of P53, MDM2, MDM4; Increasing } \\
\text { ER-dependent signaling }\end{array}$ \\
\hline & & MAGE-A3 & $\begin{array}{l}\text { Non-small-cell lung cancer; hepatocellular } \\
\text { carcinoma }\end{array}$ & $\begin{array}{l}\text { Degradation of P53, AMPKa1; Enhancing } \\
\text { TRIM28-dependent degradation of FBP1 }\end{array}$ \\
\hline & & MAGE-A4 & Hepatocellular carcinoma; lung cancer & Inactivate the oncoprotein gankyrin \\
\hline & & MAGE-A5 & Head and neck cancer; non-small-cell lung cancer & Not well characterized \\
\hline & & MAGE-A6 & Breast, colon, and lung cancer & Degradation of P53, AMPKa1 \\
\hline & & MAGE-A7 & Non-small-cell lung cancer & Not well characterized \\
\hline & & MAGE-A8 & Bladder cancer & Not well characterized \\
\hline & & MAGE-A9 & $\begin{array}{l}\text { Head and neck cancer; hepatocellular carcinoma; } \\
\text { esophageal squamous cell carcinoma; breast, } \\
\text { colorectal, lung, bladder cancer }\end{array}$ & Not well characterized \\
\hline & & MAGE-A10 & $\begin{array}{l}\text { Breast cancer; stomach cancer; melanoma; } \\
\text { esophageal and head and neck squamous } \\
\text { carcinoma; bladder, lung, hepatocellular carcinoma }\end{array}$ & Not well characterized \\
\hline & & MAGE-A11 & $\begin{array}{l}\text { Breast cancer; esophageal squamous cell } \\
\text { carcinoma; head and neck cancer; non-small } \\
\text { cell lung cancer; prostate cancer }\end{array}$ & $\begin{array}{l}\text { Increasing Skp2-mediated degradation of cyclin } \\
\text { A and p130; Decreasing Skp2-mediated } \\
\text { degradation of E2F1 and Skp2 self-ubiquitination; } \\
\text { Increasing the AR transcriptional activity }\end{array}$ \\
\hline & & MAGE-A12 & $\begin{array}{l}\text { Prostatic carcinoma and colorectal cancer; } \\
\text { melanoma, bladder, lung, esophageal } \\
\text { carcinoma; head and neck cancer }\end{array}$ & Promoting the ubiquitination of p21 \\
\hline & \multirow[t]{4}{*}{ MAGE-B } & MAGE-B1 & Hepatocellular carcinoma & Not well characterized \\
\hline & & MAGE-B2 & Hepatocellular carcinoma & Not well characterized \\
\hline & & MAGE-B3 & Colorectal cancer & Not well characterized \\
\hline & & MAGE-B4-18 & Not well characterized & Not well characterized \\
\hline & \multirow[t]{3}{*}{ MAGE-C } & MAGE-C1 & Cutaneous melanoma; breast, lung cancer & Not well characterized \\
\hline & & MAGE-C2 & $\begin{array}{l}\text { Hepatocellular carcinoma; breast, lung } \\
\text { cancer; melanoma; gastrointestinal } \\
\text { stromal tumors }\end{array}$ & $\begin{array}{l}\text { Enhancing TRIM28-dependent degradation } \\
\text { of FBP1; Inhibiting degradation of cyclinE; } \\
\text { Increasing KAP1-Ser824 phosphorylation }\end{array}$ \\
\hline & & MAGE-C3-7 & Not well characterized & Not well characterized \\
\hline \multirow[t]{11}{*}{ MAGE-II } & \multirow[t]{4}{*}{ MAGE-D } & MAGE-D1 & Breast cancer & Not well characterized \\
\hline & & MAGE-D2 & $\begin{array}{l}\text { Melanoma; gastric, colorectal cancer; } \\
\text { hepatocellular carcinoma }\end{array}$ & Suppressing TRAlL-induced apoptosis \\
\hline & & MAGE-D3 & Not well characterized & Not well characterized \\
\hline & & MAGE-D4 & $\begin{array}{l}\text { Glioma; hepatocellular carcinoma } \\
\text { Colorectal, esophageal, lung cancer }\end{array}$ & Not well characterized \\
\hline & \multirow[t]{2}{*}{ MAGE-E } & MAGE-E1 & Glioma & Not well characterized \\
\hline & & MAGE-E2-3 & Not well characterized & Not well characterized \\
\hline & MAGE-F & MAGE-F1 & $\begin{array}{l}\text { Colorectal, ovarian, breast, cervical } \\
\text { cancer; melanoma and leukemia }\end{array}$ & Not well characterized \\
\hline & MAGE-G & MAGE-G1 & Not well characterized & Not well characterized \\
\hline & MAGE-H & MAGE-H1 & Breast cancer; colorectal cancer & $\begin{array}{l}\text { Upregulating mir-200a/b expression via } \\
\text { association with p73 }\end{array}$ \\
\hline & MAGE-L2 & MAGE-L2 & Not well characterized & Not well characterized \\
\hline & NECDIN & NECDIN & $\begin{array}{l}\text { Melanoma, prostate and breast cancer; } \\
\text { leukemia; urothelial carcinoma }\end{array}$ & Repression in a STAT3-dependent manner \\
\hline
\end{tabular}




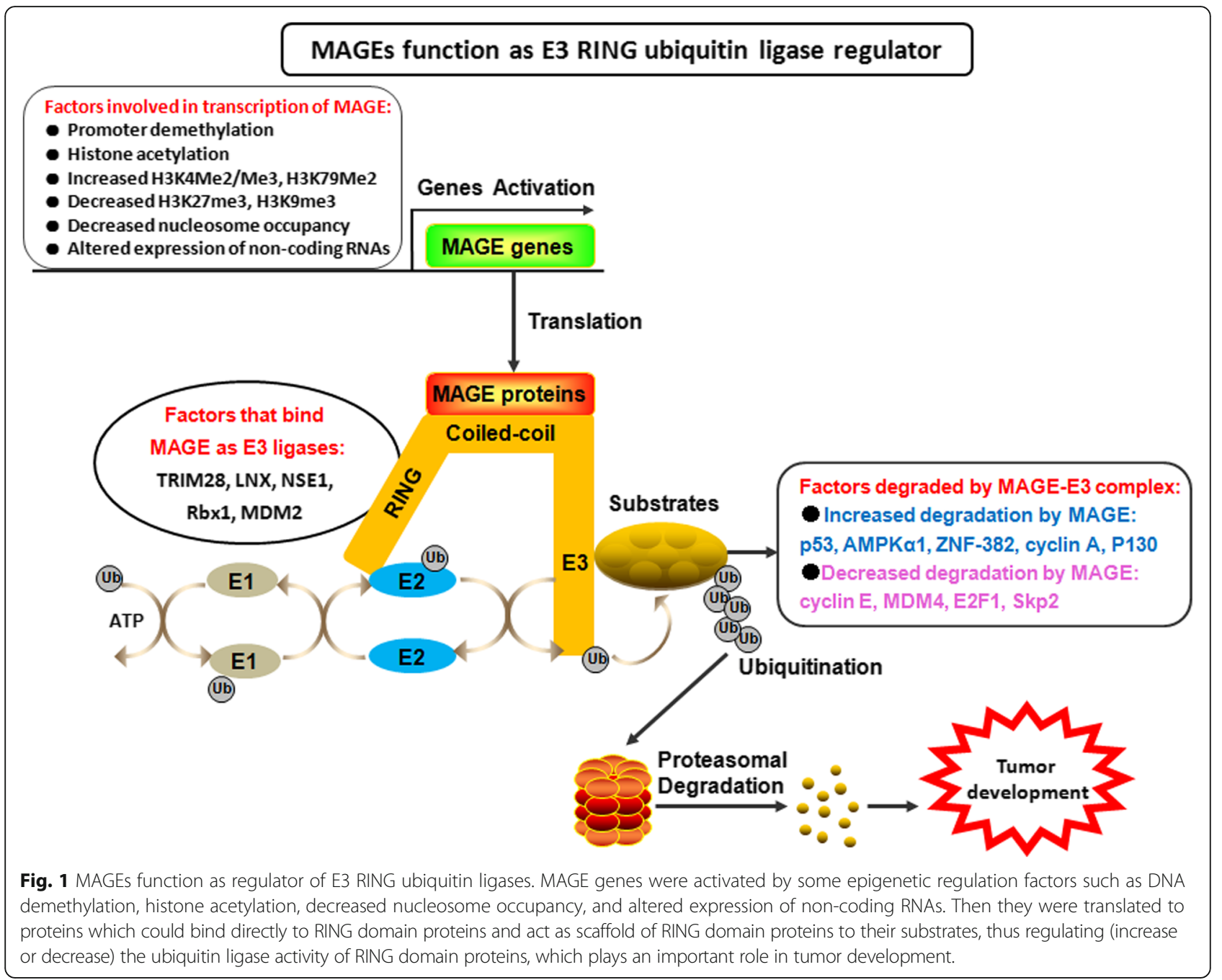

development at least in part through inhibiting p53 activation [21]. In addition, MAGE-A proteins can directly interact with $\mathrm{p} 53$. This direct interaction may occlude the binding of p53 to p53-responsive promoters, lead to the decreased p53-dependent transcription, cell cycle arrest, and apoptosis [41]. In multiple myeloma, the interaction of MAGE-A proteins with p53 was shown to inhibit apoptosis through repression of bax and stabilization of survivin [42]. MAGE-A proteins also inhibit p53 transcription functions, at least in part by recruiting HDAC3 to the binding sites of p53 promoter, leading to resistance to anti-tumor agents [43]. MAGE-A1 was reported to repress transcription through binding to ski interacting protein (SKIP), a transcription regulator, and recruiting HDAC1 [44]. Through forming complex with p53 and estrogen receptor $\alpha(E R \alpha)$, MAGE-A2 represses p53 pathway and increases ER-dependent signaling, therefore contributing to tamoxifen-resistance of ER-positive breast cancer [45] (Fig. 2-2).
MAGE-A11 was found to play a crucial role in the androgen receptor (AR) signaling network in prostate cancer. MAGE-A11 forms a complex with $\mathrm{AR}$ by binding NH2-terminal FXXLF motif of AR and increases the AR transcriptional activity by modulating $\mathrm{AR}$ interdomain interaction [46, 47]. The increased expression of MAGE-11 facilitates prostate cancer progression by enhancing ARdependent tumor growth [48]. Epidermalgrowth factor (EGF) stabilizes the AR-MAGE-A11 complex and increases androgen-dependent AR transcription activity through the site-specific phosphorylation of Thr-360, and subsequent ubiquitinylation of Lys-240 and Lys-245 within MAGE homology domain [49]. Further studies showed that the interaction between AR and MAGE-A11 is mediated by AR NH2-terminal FXXLF motif binding to a highly conserved MAGE-A11 F-box (residues 329-369) in the MAGE homology domain, and that the interaction is modulated by serum stimulation of mitogen-activated protein kinase phosphorylation of MAGE-A11 Ser-174 [50] (Fig. 2-3). In 


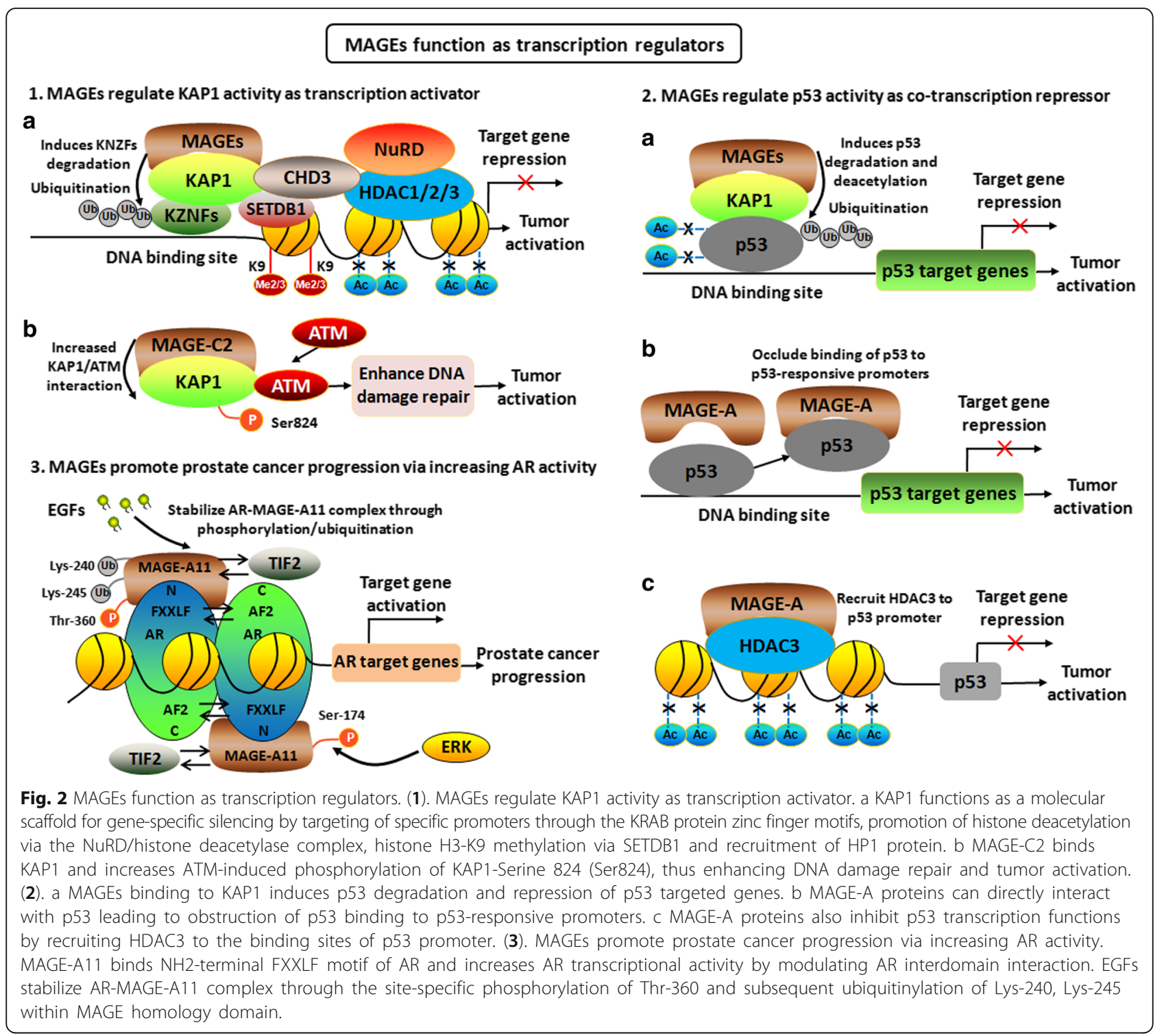

addition, MAGE-A11 also functions as a transcriptional coregulator through interacting with progesterone receptor (PR), steroid receptor-associated p300 and p160 coactivators, and contributes to cell cycle progression through interacting with p107 and E2F1 transcription factors which are important for cell cycle progression and induction of apoptosis [51, 52].

\section{Epigenetic regulation of MAGE family in cancer}

As a CTA subfamily, type I MAGE-A gene expression is restricted to cancer cells and testis. However, the precise regulatory mechanisms of MAGE family expression are still not fully understood. Epigenetic regulation seems to play an important role in MAGE expression.
DNA methylation plays critical role in the regulation of MAGEs expression

Contrary to the high homology of MAGE genes, their promoters are less homologous. These promoter regions contain some binding sites for the transcription factors. The hypermethylation of these sites may be involved in the silence of MAGE genes. For example, the promoter of MAGE-A1 gene contains binding sites for the transcription factors Ets and Sp1, whereby the Ets proteins are responsible for the high transcriptional activation. The hypermethylation of $\mathrm{CpG}$ dinucleotides on the MAGE-A promoters may prevent the binding of these activators to their motif, and consequently inhibiting the promoter activity $[53,54]$. MAGE-A1 promoter was reported to be highly methylated in somatic tissues. In contrast, it is largely unmethylated in male germ cells 
and in tumor cells that express this gene [55]. Moreover, the expression of MAGE-A1 can be induced by the demethylating agents in cells that do not express this gene. These observations suggested that DNA methylation is an essential component of MAGE-A1 repression in somatic cells. MAGE-A11 expression is increased during prostate cancer progression and castration-recurrent growth of prostate cancer, which is resulted from the hypomethylation of $\mathrm{CpG}$ sites directly proximal to the MAGE-A11 transcription start site (TSS) [54]. MAGE-A11 expression is also correlated with DNA hypomethylation at its TSS in epithelial ovarian cancer, which is associated with the global DNA hypomethylation [54]. The demethylating agent decitabine was able to reduce MAGE-A11 promoter methylation levels. Its promoter activity is partially dependent on the transcription factor Sp1. Sp1 inhibitor mithramycin A (MitA) could cause a dose-dependent reduction in MAGE-A11 promoter activity and endogenous MAGE-A11 expression. In addition, DNA demethylating agent-mediated MAGE-A11 induction could be inhibited by MitA treatment [56]. Taken together, DNA methylation plays a primary role in MAGE-A11 gene silencing.

In mammalian, DNA methylation is regulated by two DNA methyltransferases (DNMTs) families: the so-called "de novo" methyltransferase of DNMT3 family and the "maintenance" methyltransferase DNMT1 [57]. In colon cancer cells, genetic knockout of DNMT1 caused moderate activation of X-link cancer/germline (CG-X) genes including MAGE-A1, NY-ESO-1, and XAGE-1, and DNMT3b knockout had a negligible effect on CG-X gene activation. However, double knockout of DNMT1 and DNMT3b caused dramatic hypomethylation of promoters and robust induction of these CG-X genes [58]. Similarly, in MZ2MEL cells, down-regulation of DNMT1, but not DNMT3A and DNMT3B, induced the activation of MAGE-A1 gene, suggesting that DNMT1 has a predominant role for methylation maintenance of MAGE-A1 [59]. Therefore, both DNMT1 and DNMT3 family, participate in, and are necessary for, effective $\mathrm{CpG}$ island hypermethylation of MAGE genes.

Some methyl-CpG-binding domain (MBD) proteins, which are able to bind methylated DNA, have been reported to contribute to the silencing of MAGE-A genes as modulator [60]. Most hypermethylated promoters are occupied by MBD proteins, whereas unmethylated promoters generally lack MBDs. Treatment of demethylating agents causes hypomethylation of CpG islands, MBD release, and gene re-activation, reinforcing the notion that the association of MBDs with methylated promoters is methylation-dependent [61]. In all MBD-containing proteins, MBD1 differs from other members due to its unique structure and specific function in gene regulation. Except for the conserved MBD domain at its $\mathrm{N}$-terminal, it also has a transcriptional repression domain (TRD) at its C-terminal [62]. These two domains are related to the interaction between MBD1 and other proteins. However, the MBD domain mediates the binding of MBD1 to the methylated DNA, but the TRD domain regulates the transcriptional repression of target genes. In addition, MBD1 has two or three specific CXXC domains distinct from other MBD-containing proteins. The number of CXXC motifs varies among different MBD1 isoforms and depends on whether MBD1 binds to the unmethylated DNA. The first two CXXC domains (CXXC1 and CXXC2) allow MBD1 to bind to the methylated DNA, but the presence of the third CXXC domain (CXXC3) enables MBD1 to bind to DNA irrespective of its methylation status [63]. MBD1 binds to methylated as well as unmethylated MAGE-A gene promoters, and leads to the repression of the promoters. Repression of unmethylated genes depends on the third CXXC domain, and repression of methylated genes requires the MBD domain. MBD1mut, which lacks the MBD domain and harbors a non-functional TRD, showed no effect on MAGE-A gene expression [60]. The isoform MBD1v1 which contains the additional third CXXC domain could repress MAGE-A gene promoters regardless of their methylation status. However, although MBD1v3 lacks the third CXXC domain, it also has a weak repression on the unmethylated MAGE-A gene promoters, suggesting that the two other CXXC domains may also contribute to the repression of unmethylated MAGE-A promoters, however, with a weaker affinity [60]. These two kinds of binding to both methylated and unmethylated DNA enable MBD1 to act in different epigenetic regulations for MAGE-A genes. Another methyl-CpG binding protein, $\mathrm{MeCP} 2$, was also found to regulate MAGE-A11 expression in ESCC progression [64].

MAGE-A gene promoters contain Ets motifs, and the transcription factor Ets has been shown to be responsible for the high transcriptional activation of MAGE-A1 [65]. Ets-1 over-expression could result in the activation of MAGE-A promoters. However, the trans-activator Ets-1 could not abrogate the MBD-1 mediated suppression, suggesting that binding of MBD1 to the unmethylated MAGE-A gene promoter lead to gene repression which could not be abrogated by Ets-1 [60]. MAGE-A11 was also reported to be stimulated via DNA demethylation, histone acetylation and histone methylation, resulting in strengthened ESCC proliferation [64]. These data revealed why promoter demethylation results in the activation of MAGE-A genes. In general, DNA methylation is dominant over other epigenetic mechanisms for CTA (including MAGE) gene repression [66]. 
Post-translational modifications of histone play accessory roles in the regulation of MAGE expression

DNA methylation is intertwined with the post translational modification of histone [67]. Although hypermethylation of CpG-rich MAGE-A promoters plays a crucial role in the silencing of MAGE-A genes, several studies have shown that up-regulation of MAGE-A genes could not be always observed, although tumor cells were treated by the DNA methylase inhibitor DAC. Histone deacetylases inhibitor trichostatin A (TSA) was able to significantly up-regulate DAC-induced MAGE-A gene transcription, although treatment of several tumor cells with TSA alone had only small influence on MAGE-A gene expression, suggesting that histone deacetylation, which leads to a compact and transcriptionally inactive chromatin structure, also contributes to the repression of MAGE genes [58, 68]. The increased abundance of Ac-H3K9 at MAGE-A gene promoters correlates with increased MAGE-A gene expression. In addition, dual DNMT1/DNMT3b knockout resulted in large increases of AC-H3K9 level at MAGE-A promoters, which correlated with increased MAGE-A expression in cells [58]. Fibroblast growth factor receptor 2-IIIb (FGFR2-IIIb) could suppress MAGE-A3/A6 gene expression through increasing histone deacetylation and histone methylation in thyroid cancer [69]. These studies suggested that not only DNA hypermethylation but also histone deacetylation is responsible for the mechanism underlying MAGE-A gene silencing. Histone deacetylation could lead to a compact and transcriptional inactive chromatin structure, which is involved in the partial repression of MAGE-A genes in tumor cells and may impede their activation. However, in the DNA hypermethylated cells, MAGE-A genes could not be induced by TSA, suggesting that DNA methylation plays a primary role in MAGE-A gene repression, and histone deacetylation plays an accessory role in cells with hypermethylated MAGE-A genes (Fig. 3).

Histone lysine methylation also affects MAGE genes expression in cancer cells [70]. The increased level of H3K9me2 at MAGE-A promoters correlates with a lack of gene expression, whereas an increased abundance of H3K4me2 at these promoters correlates with increased MAGE-A gene expression [59]. MAGE-A high-expressed tumor cells exhibited increased occupancy of RNA polymerase II, enrichment of euchromatin/activation marks such as H3K4Me2, H3K4Me3, H3K79Me2, total H3Ac, H3K9Ac, toal H4Ac, and H4K16Ac, with decreased occupancy of SirT1 as well as polycomb repressor complex (PRC-2) components (KMT6, EED, and SUZ12), and associated PRC-2 mediated repression mark, H3K27me3 [64]. Knockdown of LSD-1 (KDM1) and JARID1B (KDM5B) that mediate demethylation of mono-, di-, and trimethylated H3K4, or the histone lysine methytransferase KMT6 that mediateds trimethylation of H3K27 significantly enhanced DAC-mediated activation of MAGE-A genes in lung cancer cells [70]. DZNep, as an EZH2 inhibitor, could decrease KMT6 and H3K27me3 levels within MAGE-A promoters, and significantly enhanced DAC-mediated induction of MAGE-A genes (Fig. 3).

\section{Nucleosome occupancy in the regulation of MAGE expression}

Nucleosomes are the basic structural units of eukaryotic chromatin [71]. Increasing evidences revealed that nucleosomes and their position, in concert with other epigenetic mechanisms, such as DNA methylation, histone modifications, changes in histone variants, as well as small noncoding regulatory RNAs, play essential roles in the control of gene expression [72]. Most importantly, nucleosomes are depleted at promoter, enhancer, and terminator regions, which allow the access of transcription factors and other regulatory proteins [73, 74]. Nucleosome occupancy and positioning are dynamic processes during development as well as in response to different environmental conditions. Therefore, nucleosome positioning and occupancy are determined by combined action of DNA sequence features, transcription factors, chromatin remodelers, and histone modifications [75]. Nucleosome positioning can direct DNA methylation patterns, whereas DNA methylation also can dictate nucleosome occupancy at numerous genomic loci in human cancer cells [76]. For the epigenetic regulation of MAGE-A11, DNA methylation regulates nucleosome occupancy specifically at the -1 positioned nucleosome of MAGEA11. Methylation of a single Ets site near the transcriptional start site correlated with -1 nucleosome occupancy and, by itself, strongly repressed MAGEA11 promoter activity. Thus, DNA methylation regulates nucleosome occupancy at MAGEA11, and this appears to function cooperatively with sequence-specific transcription factors to regulate MAGE-A11 gene expression [56].

\section{Crosstalk between DNA methylation, histone modifications, and nucleosome occupancy}

In addition to performing their individual roles, DNA methylation, histone modifications, and nucleosome occupancy work together at multiple levels to determine gene expression status [77]. The crosstalk between DNA methylation and histone modifications can occur in two ways. Firstly, DNA methylation established can lead to the recruitment of MBPs and other transcription regulatory proteins. These proteins can recruit the "writers" of histone modifications followed by the recruitment of "readers" and/ or "erasers". Secondly, histone modifications can directly or indirectly recruit the methyl writers (such as DNMTs) to establish DNA methylation. Furthermore, DNA methylation and nucleosome positioning appear to be linked with 


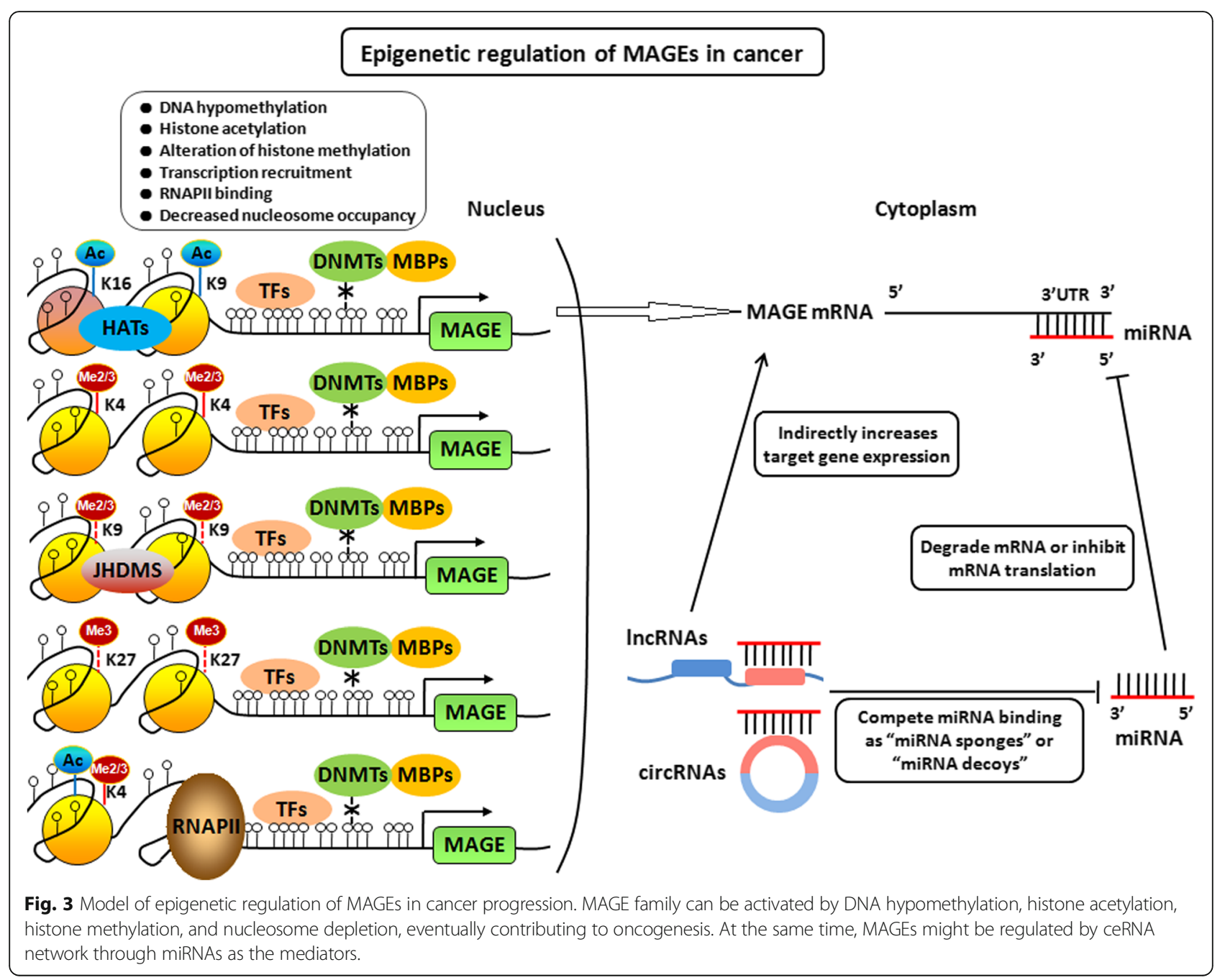

transcription factor binding and gene expression in a complex manner $[78,79]$. The crosstalk between DNA methylation, histone modifications, and nucleosome occupancy further enhance the complexity of epigenetic regulation of MAGE gene expression, which determines and maintains their function in cancer cells (Fig. 3).

\section{Non-coding RNAs including microRNAs (miRNAs) and competing endogenous RNA (ceRNA) regulate MAGEs expression in cancer progression}

It has been demonstrated that approximately $5-10 \%$ of the sequence is transcribed in human genome. Among transcripts, about $10-20 \%$ are the protein-coding RNAs, and the rest $80-90 \%$ are non-protein-coding RNAs (ncRNAs). MAGE family was also regulated by ncRNAs. MiRNAs, a novel class of gene regulator, are a class of small non-coding RNAs of $\sim 22$ nucleotides in length that regulate gene expression through post-transcriptional silencing of target genes [80]. Sequence-specific base pairing of miRNAs with $3^{\prime}$ untranslated region (3'UTR) of target
mRNA within the RNA-induced silencing complex results in the degradation or translational inhibition of target mRNAs [81]. There also exist a lot of miRNAs-binding sites at the 3'UTR of MAGE gene mRNAs. MiR-34a was reported to directly bind the 3'UTR of several MAGE-A mRNAs including MAGE-A2, -A3, -A6, and -A12, and thus inhibiting the expression of MAGE-A members [82]. In addition, miR-874 could directly bind the 3'UTR of MAGE-C2 and at least in part negatively regulate the expression of MAGE-C2 in cancer cells [83]. In addition, miRNAs can also modulate epigenetic regulatory mechanisms in cells by targeting enzymes responsible for DNA methylation or histone modifications, which potentially could indirectly influence MAGE expressions [84, 85].

For many years, it is believed that miRNAs regulate gene expression in a simple "miRNA $\rightarrow$ mRNA $\rightarrow$ protein" pattern. However, in recent years, it has been found that some RNAs contain the same conservative miRNA binding sites and reduce miRNA availability for its mRNA targets by competing for miRNA binding as "miRNA 
sponges" or "miRNA decoys" $[86,87]$. Based on these finding, the competing endogenous RNA hypothesis was proposed [88]. According to the ceRNA hypothesis, the role of miRNAs in regulating gene expression has thus been amended from that of an "initiator" to a "mediator," and the regulation pattern has been amended from "miR$\mathrm{NA} \rightarrow \mathrm{mRNA}$ " to network-based "ceRNAs $\rightarrow$ miRNAs $\rightarrow \mathrm{mR}$ NAs" [89]. Long non-coding RNAs (lncRNAs), circular RNAs (circRNAs), mRNAs and pseudogene transcripts are all revealed to act as ceRNAs and regulate the target genes by competing for the same miRNAs in the available miRNA pools [90-93]. In our recent study, MAGE-A family was found to be regulated by the circRNAmiRNA-mRNA axis in ESCC progression [94]. Taken together, MAGE family might be regulated by ceRNA network through miRNAs as the mediators (Fig. 3).

\section{Conclusion}

MAGEs are expressed in a variety of human cancers, and drive tumor progression through various mechanisms, which eventually results in the tumor growth, metastasis, and recurrence. Although recent studies have made great progress towards elucidating the epigenetic regulation of MAGE family, the transcriptional programs controlling their aberrant expression are still not fully understood and much yet is to be discovered. More mechanism studies concerning MAGE function and regulation will provide some new alternative strategies targeting MAGEs in multiple types of cancers.

\section{Abbreviations \\ 3'UTR: 3' Untranslated region; AR: Androgen receptor; ATM: Ataxia-telangiectasia- mutated; CG-X: X-link cancer/germline; CNS: Central nervous system; CTAs: Cancer-testis antigens; DNMTs: DNA methyltransferases; EGF: Epidermalgrowth factor; ERa: Estrogen receptor a; FGFR2-IIIb: Fibroblast growth factor receptor 2-IIIb; H3K9me3: Histone 3 lysine 9 trimethylation; KZNFs: KRAB domain zinc finger transcription factors; IncRNAs: Long non-coding RNAs; MAGE: Melanoma Antigens Genes; MBD: Methyl-CpG binding domain; MitA: Mithramycin A; ncRNAs: Non-protein-coding RNAs; PR: Progesterone receptor; PRC-2: Polycomb repressor complex; Rbx1: RING Box protein-1; SKIP: Ski interacting protein; TRD: Transcriptional repression domain; TSA: Histone deacetylases inhibitor trichostatin A; TSS: Transcription start site}

\section{Acknowledgements}

The authors would like to greatly appreciate Dr. Qianglin Duan, a skilled English proofreader from Tongji University for paper revision. We also apologize to many authors whose work could not be cited due to space limitations. We recognize that our conclusions are based on the efforts of many.

\section{Funding}

This work was supported by Nature Science Foundation of Hebei Province (no. 2016206410).

\section{Availability of data and materials}

The data and material are available in the article.

\section{Authors' contributions}

$Y L, L M$, and PD acquired the materials and wrote the manuscript draft. SM designed the draft, and reviewed and edited the manuscript. All authors read and approved the final manuscript.
Ethics approval and consent to participate

Not applicable.

\section{Consent for publication}

All authors are consent for publication.

\section{Competing interests}

The authors declare that they have no competing interests.

\section{Publisher's Note}

Springer Nature remains neutral with regard to jurisdictional claims in published maps and institutional affiliations.

Received: 16 July 2018 Accepted: 30 August 2018

Published online: 05 September 2018

\section{References}

1. Van d BP, Traversari C, Chomez P, Lurquin C, De Plaen E, Van den Eynde B, et al. A gene encoding an antigen recognized by cytolytic $T$ lymphocytes on a human melanoma. Science. 1991;254:1643-7.

2. Chomez P, De BO, Bertrand M, De PE, Boon T, Lucas S. An overview of the MAGE gene family with the identification of all human members of the family. Cancer Res. 2001;61:5544-51.

3. Barker PA, Salehi A. The MAGE proteins: emerging roles in cell cycle progression, apoptosis, and neurogenetic disease. J Neurosci Res. 2002;67:705-12.

4. Anna KL, Patrick RP. A comprehensive guide to the MAGE family of ubiquitin ligases. J Mol Biol 2017; 429:1114-1142.

5. Sang M, Wang L, Ding C, Zhou X, Wang B, Wang L, et al. Melanomaassociated antigen genes - an update. Cancer Lett. 2011;302:85-90.

6. Simpson AJ, Caballero OL, Jungbluth A, Chen YT, Old LJ. Cancer/testis antigens, gametogenesis and cancer. Nat Rev Cancer. 2005;5:615-25.

7. Wang D, Wang J, Ding N, Li Y, Yang Y, Fang $X$, et al. MAGE-A1 promotes melanoma proliferation and migration through C-JUN activation. Biochem Biophys Res Commun. 2016;473:959-65.

8. Lian Y, Sang M, Ding C, Zhou X, Fan X, Xu Y, et al. Expressions of MAGE-A10 and MAGE-A11 in breast cancers and their prognostic significance: a retrospective clinical study. J Cancer Res Clin Oncol. 2012;138:519-27.

9. Heninger E, Krueger TE, Thiede SM, Sperger JM, Byers BL, Kircher MR, et al. Inducible expression of cancer-testis antigens in human prostate cancer. Oncotarget. 2016;7:84359-74.

10. Sang $M$, Gu L, Yin D, Liu F, Lian Y, Zhang $X$, et al. MAGE-A family expression is correlated with poor survival of patients with lung adenocarcinoma: a retrospective clinical study based on tissue microarray. J Clin Pathol. 2017; 70:533-40.

11. Sang M, Gu L, Liu F, Lian Y, Yin D, Fan X, et al. Prognostic significance of MAGE-A11 in esophageal squamous cell carcinoma and identification of related genes based on DNA microarray. Arch Med Res. 2016;47:151-61.

12. Ogata K, Aihara R, Mochiki E, Ogawa A, Yanai M, Toyomasu Y, et al. Clinical significance of melanoma antigen-encoding gene-1 (MAGE-1) expression and its correlation with poor prognosis in differentiated advanced gastric cancer. Ann Surg Oncol. 2011;18:1195-203.

13. Mengus C, Schultz-Thater E, Coulot J, Kastelan Z, Goluza E, Coric M, et al. MAGE-A10 cancer/testis antigen is highly expressed in high-grade nonmuscle-invasive bladder carcinomas. Int J Cancer. 2013;132:2459-63.

14. Sang M, Wu X, Fan X, Sang M, Zhou X, Zhou N. Multiple MAGE-A genes as surveillance marker for the detection of circulating tumor cells in patients with ovarian cancer. Biomarkers. 2014;19:34-42.

15. Gu X, Fu M, Ge Z, Zhan F, Ding Y, Ni H, et al. High expression of MAGE-A9 correlates with unfavorable survival in hepatocellular carcinoma. Sci Rep. 2014;4:6625

16. Scarcella DL, Chow CW, Gonzales MF, Economou C, Brasseur F, Ashley DM. Expression of MAGE and GAGE in high-grade brain tumors: a potential target for specific immunotherapy and diagnostic markers. Clin Cancer Res. 1999:5:335-41

17. Osterlund C, Tohonen V, Forslund KO, Nordqvist K. Mage-b4, a novel melanoma antigen (MAGE) gene specifically expressed during germ cell differentiation. Cancer Res. 2000;60:1054-61.

18. Gjerstorff MF, Harkness L, Kassem M, Frandsen U, Nielsen O, Lutterodt M, et al. Distinct GAGE and MAGE-A expression during early human development indicate specific roles in lineage differentiation. Hum Reprod. 2008;23:2194-201 
19. Yang B, O'Herrin S, Wu J, Reagan-Shaw S, Ma Y, Nihal M, et al. Select cancer testes antigens of the MAGE-A, $-B$, and $-C$ families are expressed in mast cell lines and promote cell viability in vitro and in vivo. J Invest Dermatol. 2007; 127:267-75.

20. Liu W, Cheng S, Asa SL, Ezzat S. The melanoma-associated antigen A3 mediates fibronectin-controlled cancer progression and metastasis. Cancer Res. 2008;68:8104-12.

21. Yang B, O'Herrin SM, Wu J, Reagan-Shaw S, Ma Y, Bhat KM, et al. MAGE-A, mMage-b, and MAGE-C proteins form complexes with KAP1 and suppress p53-dependent apoptosis in MAGE-positive cell lines. Cancer Res. 2007;67: 9954-62.

22. Pineda CT, Ramanathan S, Fon TK, Weon JL, Potts MB, Ou YH, et al. Degradation of AMPK by a cancer-specific ubiquitin ligase. Cell. 2015;160:715-28.

23. Doyle JM, Gao J, Wang J, Yang M, Potts PR. MAGE-RING protein complexes comprise a family of E3 ubiquitin ligases. Mol Cell. 2010;39:963-74.

24. Feng Y, Gao J, Yang M. When MAGE meets RING: insights into biological functions of MAGE proteins. Protein Cell. 2011;2:7-12

25. Borden KL. RING domains: master builders of molecular scaffolds? J Mol Biol. 2000;295:103-1112

26. Lorick KL, Jensen JP, Fang S, Ong AM, Hatakeyama S, Weissman AM. RING fingers mediate ubiquitin-conjugating enzyme (E2)-dependent ubiquitination. Proc Natl Acad Sci U S A. 1999;6:364-11369.

27. Jackson PK, Eldridge AG, Freed E, Furstenthal L, Hsu JY, Kaiser BK, et al. The lore of the RINGs: substrate recognition and catalysis by ubiquitin ligases. Trends Cell Biol. 2000;10:429-39.

28. Pineda CT, Potts PR. Oncogenic MAGEA-TRIM28 ubiquitin ligase downregulates autophagy by ubiquitinating and degrading AMPK in cancer. Autophagy. 2015;112:844-6.

29. Xiao TZ, Bhatia N, Urrutia R, Lomberk GA, Simpson A, Longley BJ. MAGE I transcription factors regulate KAP1 and KRAB domain zinc finger transcription factor mediated gene repression. PLoS One. 2011;6:e23747.

30. Angelo L, Elena C, Giorgia M, Diana Z, Paola L, Paola C. KRAB-zinc finger proteins: a repressor family displaying multiple biological functions. Curr Genomics. 2013;14:268-78.

31. Bhatia N, Yang B, Xiao TZ, Peters N, Hoffmann MF, Longley BJ. Identification of novel small molecules that inhibit protein-protein interactions between MAGE and KAP-1. Arch Biochem Biophys. 2011;508:217-21.

32. Zheng N, Schulman BA, Song L, Mille JJ, Jeffrey PD, Wang P, et al. Structure of the Cul1-Rbx1-Skp1-F boxSkp2 SCF ubiquitin ligase complex. Nature. 2002:416:703-9.

33. Nakayama Kl, Nakayama K. Ubiquitin ligases: cell-cycle control and cancer. Nat Rev Cancer. 2006;6:369-81

34. Petroski MD, Deshaies RJ. Function and regulation of cullin-RING ubiquitin ligases. Nat Rev Mol Cell Biol. 2005;6:9-20.

35. Hao J, Song X, Wang J, Guo C, Li Y, Li B, et al. Cancer-testis antigen MAGE$\mathrm{C} 2$ binds $\mathrm{Rbx} 1$ and inhibits ubiquitin ligase-mediated turnover of cyclin $\mathrm{E}$. Oncotarget. 2015;6:42028-39.

36. Marcar L, Ihrig B, Hourihan J, Bray SE, Quinlan PR, Jordan LB, et al. MAGE-A cancer/testis antigens inhibit MDM2 ubiquitylation function and promote increased levels of MDM4. PLoS One. 2015;10:e0127713.

37. Su S, Chen X, Geng J, Bray SE, Quinlan PR, Jordan LB, et al. Melanoma antigen-A11 regulates substrate-specificity of Skp2-mediated protein degradation. Mol Cell Endocrinol. 2017:439:1-9.

38. Bhatia N, Xiao TZ, Rosenthal KA, Siddiqui IA, Thiyagarajan S, Smart B, et al. MAGE-C2 promotes growth and tumorigenicity of melanoma cells, phosphorylation of KAP1, and DNA damage repair. J Invest Dermatol. 2013; 133:759-67.

39. Schultz DC, Ayyanathan K, Negorev D, Maul GG, Rauscher FJ 3rd. SETDB1: a novel KAP-1-associated histone $\mathrm{H3}$, lysine 9-specific methyltransferase that contributes to HP1-mediated silencing of euchromatic genes by KRAB zincfinger proteins. Genes Dev. 2002;16:919-32.

40. Li X, Lee YK, Jeng JC, Yen Y, Schultz DC, Shih HM, et al. Role for KAP1 serine 824 phosphorylation and sumoylation/desumoylation switch in regulating KAP1-mediated transcriptional repression. J Biol Chem. 2007:282:36177-89.

41. Marcar L, Maclaine NJ, Hupp TR, Meek DW. Mage-A cancer/testis antigens inhibit p53 function by blocking its interaction with chromatin. Cancer Res. 2010;70:10362-70

42. Nardiello $T$, Jungbluth AA, Mei A, Diliberto $M$, Huang $X$, Dabrowski $A$ et al. MAGE-A inhibits apoptosis in proliferating myeloma cells through repression of bax and maintenance of survivin. Clin Cancer Res. 2011; $17: 4309-19$
43. Monte M, Simonatto M, Peche LY, Bublik DR, Gobessi S, Pierotti MA, et al. MAGE-A tumor antigens target p53 transactivation function through histone deacetylase recruitment and confer resistance to chemotherapeutic agents. Proc Natl Acad Sci U S A. 2006;103:11160-5.

44. Laduron S, Deplus R, Zhou S, Kholmanskikh O, Godelaine D, De Smet C, et al. MAGE-A1 interacts with adaptor SKIP and the deacetylase HDAC1 to repress transcription. Nucleic Acids Res. 2004;32:4340-50.

45. Wong PP, Yeoh CC, Ahmad AS, Chelala C, Gillett C, Speirs V, et al. Identification of MAGEA antigens as causal players in the development of tamoxifen-resistant breast cancer. Oncogene. 2014;33:4579-88.

46. Bai S, Grossman G, Yuan L, Lessey BA, French FS, Young SL, et al. Hormone control and expression of androgen receptor coregulator MAGE-11 in human endometrium during the window of receptivity to embryo implantation. Mol Human Reprod. 2008;14:107-16.

47. Bai S, Wilson EM. Epidermal-growth-factor-dependent phosphorylation and ubiquitinylation of MAGE-11 regulates its interaction with the androgen receptor. Mol Cell Biol. 2008;28:1947-63.

48. Wilson EM. Androgen receptor molecular biology and potential targets in prostate cancer. Ther Adv Urol. 2010;2:105-17.

49. Bai $\mathrm{S}, \mathrm{He} \mathrm{B}$, Wilson EM. Melanoma antigen gene protein MAGE-11 regulates androgen receptor function by modulating the interdomain interaction. Mol Cell Biol. 2005;25:1238-57.

50. Askew EB, Bai S, Hnat AT, Minges JT, Wilson EM. Melanoma antigen gene protein-A11 (MAGE-11) F-box links the androgen receptor NH2-terminal transactivation domain to p160 coactivators. J Biol Chem. 2009;284:34793-808.

51. Su S, Blackwelder AJ, Grossman G, Minges JT, Yuan L, Young SL, et al. Primate-specific melanoma antigen-A11 regulates isoform-specific human progesterone receptor-B transactivation. J Biol Chem. 2012;287:34809-24.

52. Su S, Minges JT, Grossman G, Blackwelder AJ, Mohler JL, Wilson EM. Protooncogene activity of melanoma antigen-A11 (MAGE-A11) regulates retinoblastoma-related p107 and E2F1 proteins. J Biol Chem. 2013;288:24809-24.

53. De Smet $C$, Lurquin $C$, Lethé $B$, Martelange $V$, Boon T. DNA methylation is the primary silencing mechanism for a set of germ line- and tumor-specific genes with a CpG-rich promoter. Mol Cell Biol. 1999;19:7327-35.

54. Karpf AR, Bai S, James SR, Mohler JL, Wilson EM. Increased expression of androgen receptor coregulator MAGE-11 in prostate cancer by DNA hypomethylation and cyclic AMP. Mol Cancer Res. 2009;7:523-35.

55. De Smet C, Loriot A, Boon T. Promoter-dependent mechanism leading to selective hypomethylation within the $5^{\prime}$ region of gene MAGE-A1 in tumor cells. Mol Cell Biol. 2004;24:4781-90.

56. Smitha RJ, Carlos DC, Ashok S, Wa Z, James LM, Kunle O, et al. DNA methylation and nucleosome occupancy regulate the cancer germline antigen gene MAGEA11. Epigenetics. 2013;8:849-63.

57. Elliott EN, Sheaffer KL, Kaestner KH. The 'de novo' DNA methyltransferase Dnmt3b compensates the Dnmt1-deficient intestinal epithelium. Elife. 2016;5.

58. James SR, Link PA, Karpf AR. Epigenetic regulation of X-linked cancer/ germline antigen genes by DNMT1 and DNMT3b. Oncogene. 2006;25: 6975-85.

59. Loriot A, De PE, Boon T, De Smet C. Transient down-regulation of DNMT1 methyltransferase leads to activation and stable hypomethylation of MAGEA1 in melanoma cells. J Biol Chem. 2006;281:10118-26.

60. Wischnewski F, Friese O, Pantel K, Schwarzenbach $\mathrm{H}$. Methyl-CpG binding domain proteins and their involvement in the regulation of the MAGE-A1, MAGE-A2, MAGE-A3, and MAGE-A12 gene promoters. Mol Cancer Res. 2007; 5:749-59.

61. Lopez-Serra L, Ballestar E, Fraga MF, Alaminos M, Setien F, Esteller M. A profile of methyl-CpG binding domain protein occupancy of hypermethylated promoter CpG islands of tumor suppressor genes in human cancer. Cancer Res. 2006;66:8342-6.

62. $\mathrm{Ng} \mathrm{HH}$, Jeppesen $\mathrm{P}$, Bird A. Active repression of methylated genes by the chromosomal protein MBD1. Mol Cell Biol. 2000:20:1394-406.

63. Jorgensen HF, Ben-Porath I, Bird AP. MBD1 is recruited to both methylated and nonmethylated CpGs via distinct DNA binding domains. Mol Cell Biol. 2004;24:3387-95.

64. Liu S, Liu F, Huang W, Gu L, Meng L, Ju Y, et al. MAGE-A11 is activated through TFCP2/ZEB1 binding sites demethylation as well as histone modification and facilitates ESCC tumor growth. Oncotarget. 2017;9:3365-78.

65. De Smet C, Courtois SJ, Faraoni I, Lurquin C, Szikora JP, De Backer O, et al. Involvement of two Ets binding sites in the transcriptional activation of the MAGE1 gene. Immunogenetics. 1995;42:282-90. 
66. Akers SN, Odunsi K, Karpf AR. Regulation of cancer germline antigen gene expression: implication for cancer immunotherapy. Future Oncol. 2010;6:717-32.

67. Bartke T, Vermeulen M, Xhemalce B, Robson SC, Mann M, Kouzarides T. Nuclesome-interacting proteins regulated by DNA and histone methylation. Cell. 2010;143:470-84.

68. Wischnewski F, Pantel K, Schwarzenbach H. Promoter demethylation and histone acetylation mediate gene expression of MAGE-A1, - A2, -A3, and -A12 in human cancer cells. Mol Cancer Res. 2006:4:339-49.

69. Kondo T, Zhu X, Asa SL, Ezzat S. The cancer/testis antigen melanomaassociated antigen-A3/A6 is a novel target of fibroblast growth factor receptor 2-IIIb through histone $\mathrm{H} 3$ modifications in thyroid cancer. Clin Cancer Res. 2007;13:4713-20.

70. Rao M, Chinnasamy N, Hong JA, Zhang Y, Zhang M, Xi S, et al. Inhibition of histone lysine methylation enhances cancer-testis antigen expression in lung cancer cells: implications for adoptive immunotherapy of cancer. Cancer Res. 2011;71:4192-204.

71. Richmond TJ, Davey CA. The structure of DNA in the nucleosome core. Nature. 2003;423:145-50.

72. Andreu-Vieyra CV, Liang G. Nucleosome occupancy and gene regulation during tumorigenesis. Adv Exp Med Biol. 2013;754:109-34.

73. Bell O, Tiwari VK, Thomä NH, Schübeler D. Determinants and dynamics of genome accessibility. Nat Rev Genet. 2011;12:554-64.

74. Henikoff S. Nucleosomes at active promoters: unforgettable loss. Cancer Cell. 2007;12:407-9.

75. Lorch Y, Kornberg RD. Chromatin-remodeling and the initiation of transcription. Q Rev Biophys. 2015;48:465-70.

76. Chodavarapu RK, Feng S, Bernatavichute YV, Chen PY, Stroud H, Yu Y, et al. Relationship between nucleosome positioning and DNA methylation. Nature. 2010;466:388-92.

77. Teif VB, Beshnova DA, Vainshtein Y, Marth C, Mallm JP, Höfer T, et al. Nucleosome repositioning links DNA (de)methylation and differential CTCF binding during stem cell development. Genome Res. 2014;24:1285-95.

78. Cedar H, Bergman Y. Linking DNA methylation and histone modification: patterns and paradigms. Nat Rev Genet. 2009;10:295-304.

79. Collings CK, Anderson JN. Links between DNA methylation and nucleosome occupancy in the human genome. Epigenetics Chromatin. 2017;10:18.

80. He L, Hannon GJ. MicroRNAs: small RNAs with a big role in gene regulation. Nat Rev Genet. 2004;5:522-31.

81. Filipowicz W, Bhattacharyya SN, Sonenberg N. Mechanisms of posttranscriptional regulation by microRNAs: are the answers in sight? Nat Rev Genet. 2008;9:102-14.

82. Weeraratne SD, Amani V, Neiss A, Teider N, Scott DK, Pomeroy SL, et al. miR-34a confers chemosensitivity through modulation of MAGE-A and p53 in medulloblastoma. Neuro-Oncology. 2011;13:165-75.

83. Song X, Song W, Wang Y, Wang J, Li Y, Qian X, et al. MicroRNA-874 functions as a tumor suppressor by targeting cancer/testis antigen HCA587/ MAGE-C2. J Cancer. 2016;7:656-63.

84. Fabbri M, Garzon R, Cimmino A, Liu Z, Zanesi N, Callegari E, et al. MicroRNA29 family reverts aberrant methylation in lung cancer by targeting DNA methyltransferases 3A and 3B. Proc Natl Acad Sci U S A. 2007;104:15805-10.

85. Friedman JM, Liang G, Liu CC, Wolff EM, Tsai YC, Ye W, et al. The putative tumor suppressor microRNA-101 modulates the cancer epigenome by repressing the polycomb group protein EZH2. Cancer Res. 2009;69:2623-9.

86. Ebert MS, Neilson JR, Sharp PA. MicroRNA sponges: competitive inhibitors of small RNAs in mammalian cells. Nat Methods. 2007:4:721-6.

87. Poliseno L, Salmena L, Zhang J, Carver B, Haveman WJ, Pandolfi PP. A coding-independent function of gene and pseudogene mRNAs regulates tumour biology. Nature. 2010;465:1033-8.

88. Salmena L, Poliseno L, Tay Y, Kats L, Pandolfi PP. A ceRNA hypothesis: the Rosetta stone of a hidden RNA language? Cell. 2011;146:353-8.

89. Yang C, Wu D, Gao L, Liu X, Jin Y, Wang D, et al. Competing endogenous RNA networks in human cancer: hypothesis, validation, and perspectives. Oncotarget. 2016;7:13479-90.

90. Huang M, Zhong Z, Lv M, Shu J, Tian Q, Chen J. Comprehensive analysis of differentially expressed profiles of IncRNAs and circRNAs with associated coexpression and ceRNA networks in bladder carcinoma. Oncotarget. 2016;7: 47186-200.

91. Wang W, Zhuang Q, Ji K, Wen B, Lin P, Zhao Y, et al. Identification of miRNA, IncRNA and mRNA-associated ceRNA networks and potential biomarker for MELAS with mitochondrial DNA A3243G mutation. Sci Rep. 2017;7:41639.
92. Hansen TB, Jensen TI, Clausen BH, Bramsen JB, Finsen B, Damgaard CK, et al Natural RNA circles function as efficient microRNA sponges. Nature. 2013; 495:384-8.

93. An Y, Furber KL, Ji S. Pseudogenes regulate parental gene expression via ceRNA network. J Cell Mol Med. 2017;21:185-92.

94. Sang M, Meng L, Sang Y, Liu S, Ding P, Ju Y, et al. Cicular RNA ciRS-7 accelerates ESCC progression through acting as a miR-876-5p sponge to enhance MAGE-A family expression. Cancer Lett. 2018;426:37-46.
Ready to submit your research? Choose BMC and benefit from:

- fast, convenient online submission

- thorough peer review by experienced researchers in your field

- rapid publication on acceptance

- support for research data, including large and complex data types

- gold Open Access which fosters wider collaboration and increased citations

- maximum visibility for your research: over $100 \mathrm{M}$ website views per year

At $\mathrm{BMC}$, research is always in progress.

Learn more biomedcentral.com/submissions 